\title{
Strength Analysis and Fatigue Life Prediction on Steering Knuckle
}

\author{
Hanwu Liu ${ }^{a}$, Junhong Wang ${ }^{b}$, Shengjun Fang ${ }^{c}$, Shen Li ${ }^{d}$
}

\begin{abstract}
School of Mechanical and Electrical Engineering, North China Institute of Science and Technology, Sanhe, Hebei, 065201, China
\end{abstract}

ahanwu-liu@sohu.com, bw3005208191@126.com, c383613665@qq.com, d634706031@qq.com

Keywords: Steering Knuckle; Free Modal; Strength Analysis; Fatigue Life Prediction

\begin{abstract}
In the process of operation, the loading condition of automobile steering knuckle is very complex, which seriously affects its structure strength and fatigue life. In this paper, finite element analysis is applied to calculate and analyze the deformation and stress distribution in steering knuckle under conditions of three kinds of limit load, which are impulse force induced by rough ground, longitudinal impact caused by emergency braking, transverse impact generated when the car turned. Based on this, a prediction of the fatigue life on the more than 300000 times of cyclic loading is also carried out. The results show that under the three kinds of limit load conditions, the maximum stress value of the steering knuckle of $940 \mathrm{MPa}$, which is less than the yield strength of steering knuckle materials, so the steering knuckle won't produce yield. Fatigue strength analysis shows that the fatigue life application factor is 0.9375 , less than 1 , which illustrates that fatigue damage will not occur. The study provides an important theoretical basis and technical support for the actual design and industrial production of automobile steering knuckle.
\end{abstract}

\section{Introduction}

Steering knuckle is an important part of the vehicle axle. It is subjected to a tangential load and a impact from the ground, and transfers steering force from steering knuckle, and also it is necessary to leave enough space for brake to install ABS sensor [1]. At the same time, the steering knuckle is connected to knuckle column, tie rod, shock absorber and brake caliper etc., so its structure is very complex, and the requirements in the strength, impact resistance, fatigue strength and reliability are high, therefore the research on steering knuckle life is necessary [2][3]. In motion process, vehicle parts are subjected to a variety of alternating load. The alternating load is generally lower than the tensile strength limit, so parts are not easy for strength failure, but under the effect of the alternating load repeatedly, the parts may occur crack initiation and extension and lead to sudden rupture, known as fatigue destruction. It has the extremely important significance to understand the influence of this damage form on the strength of the vehicle parts.

Most external loads withstood by rolling stock are random load which act repeatedly, on the effects of this kind of random dynamic load, many components will generate dynamic stresses and cause fatigue damage [4]. As the fatigue damage accumulated, initial cracks will occur, extend, and finally cause fracture, and this is the main form of structural damage. Thus, structural fatigue design of the rolling stock has gradually become one of the necessary processes in early time of new product development, while the prediction of the structure fatigue life through effective calculating method is an important goal of structural design [5]. This article will focus on strength analysis and fatigue life prediction on automobile steering knuckle, using the finite element simulation technology.

\section{Stress and Deformation Analysis on Steering Knuckle}

At The creation of a steering knuckle model which is like twigs uses a bottom-up modeling method, and the basic order of molding is the hub - spherical pair - damping arm - control arm -tire control point. The complete model is shown in Fig. 1. Then the following work is done, defining the type of element, setting unit cell size, material properties and other parameters, using smart meshing technology to complete knuckle model mesh, shown in Fig. 2. 


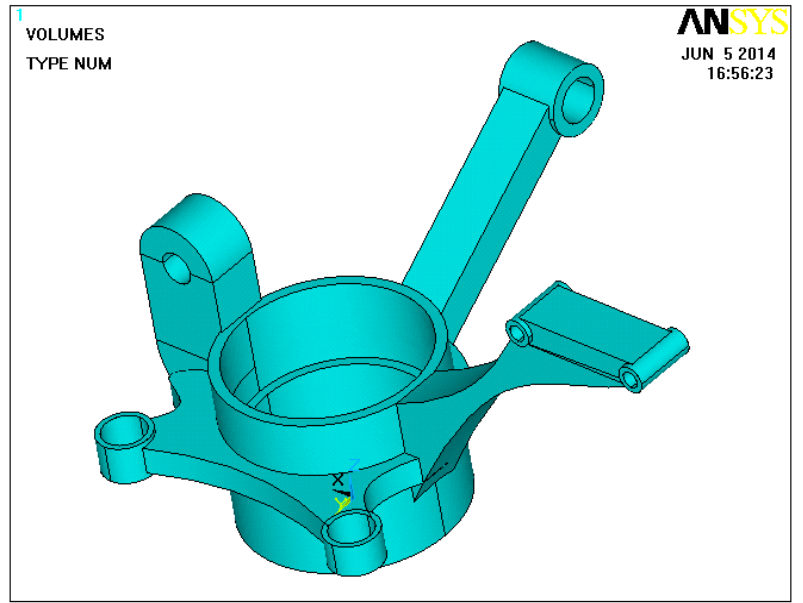

Fig. 1 Mathematical Model of Steering Knuckle

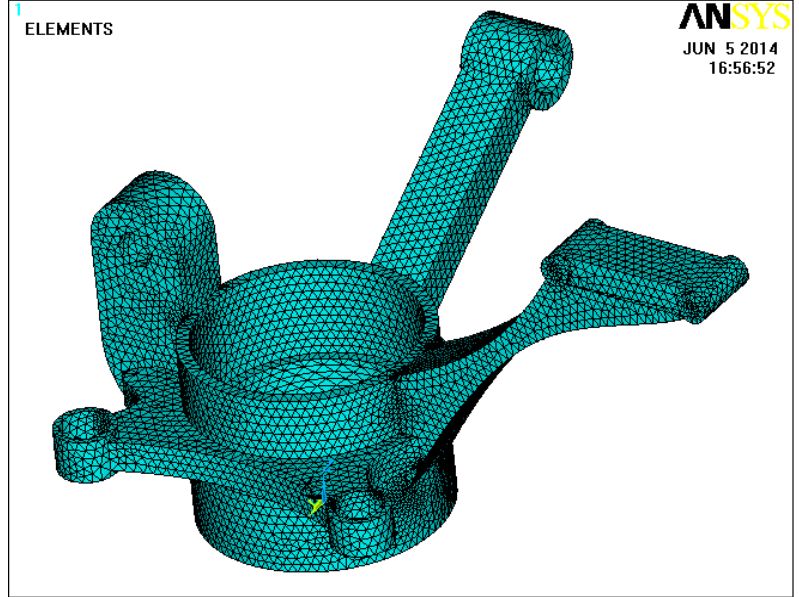

Fig. 2 Finite Element Model of Steering Knuckle

The load of automobile steering knuckle generally consists of two parts, namely, the static load generated by hanging sprung mass and the dynamic load produced during the motion process. There are three kinds of stress limit working conditions, as shown in Table 1.

Table 1 Forces of each condition at different positions

\begin{tabular}{|c|c|c|c|c|c|c|c|c|c|}
\hline \multirow{2}{*}{$\frac{\text { Condition }}{\text { Position }}$} & \multicolumn{3}{|c|}{ Condition1 } & \multicolumn{3}{|c|}{ Condition2 } & \multicolumn{3}{|c|}{ Condition3 } \\
\hline & $\begin{array}{c}\text { control } \\
\text { arm }\end{array}$ & $\begin{array}{c}\text { damping } \\
\text { arm }\end{array}$ & $\begin{array}{l}\text { spherical } \\
\text { pair }\end{array}$ & $\begin{array}{c}\text { control } \\
\text { arm }\end{array}$ & $\begin{array}{l}\text { damping } \\
\text { arm }\end{array}$ & $\begin{array}{c}\text { spherical } \\
\text { pair }\end{array}$ & $\begin{array}{l}\text { control } \\
\text { arm }\end{array}$ & $\begin{array}{c}\text { damping } \\
\text { arm }\end{array}$ & $\begin{array}{l}\text { spherical } \\
\text { pair }\end{array}$ \\
\hline $\mathrm{X}$-axis/N & 227 & -1123 & 1294 & 924 & -266 & -573 & -15497 & -4420 & -1049 \\
\hline Y-axis /N & 1109 & -6346 & 5429 & -16061 & 3375 & -3023 & 11347 & -306 & -11008 \\
\hline Z-axis /N & -193 & -19126 & -1041 & -1232 & -4627 & -230 & 908 & -4003 & -831 \\
\hline Force/N & 1148 & 20900 & 5800 & 16000 & 5700 & 3060 & 18600 & 6000 & 11000 \\
\hline \multicolumn{2}{|c|}{ Pressure/MPa 1.73} & 43.5 & 10 & 26.8 & 12 & 5 & 30 & 12.4 & 18.5 \\
\hline
\end{tabular}

Condition 1: The impact induced by impulse force during the car running on the rough road;

Condition 2: Longitudinal impact from ground and its own inertia force in an emergency brake; Condition 3: Lateral impact in turning.

This paper analyzed the force and deformation on the knuckle in the three different conditions, and the results were shown in Fig. 3, Fig. 4 and Fig. 5.

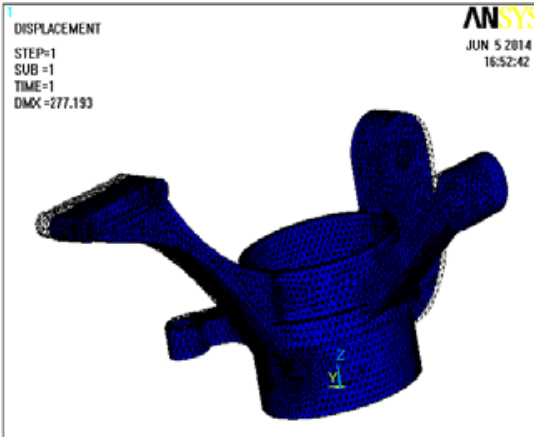

(a) Displacement Distribution Map

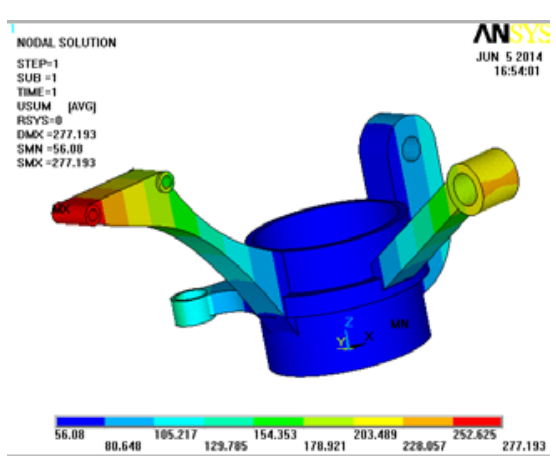

(b) Displacement Moir Map

Fig. 3 Finite Element Calculation Results in Condition 1

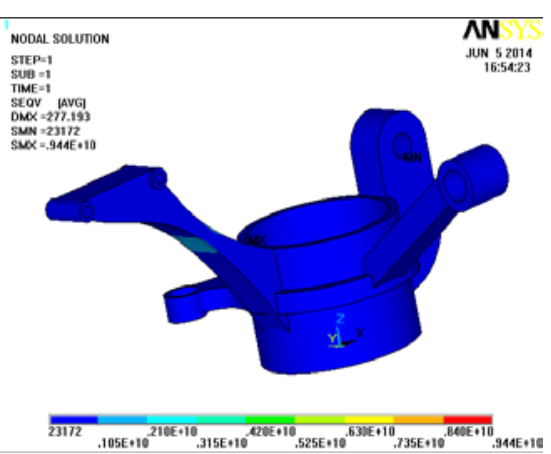

(c) Stress Distribution Map

It can be seen from Fig. 3, in condition 1, the values of deformation and displacement are largest on the top of damping arm of the steering knuckle, can reach $22.7 \mathrm{~mm}$, which shows that the design here is not very reasonable, it is necessary to increase the thickness and width of the damping arm. The maximum stress point occurs in the middle of damping arm, whose value is $940 \mathrm{MPa}$, which is 
less than material yield strength $1000 \mathrm{MPa}$, so the damping arm will not be damaged, but still needs reinforcement.

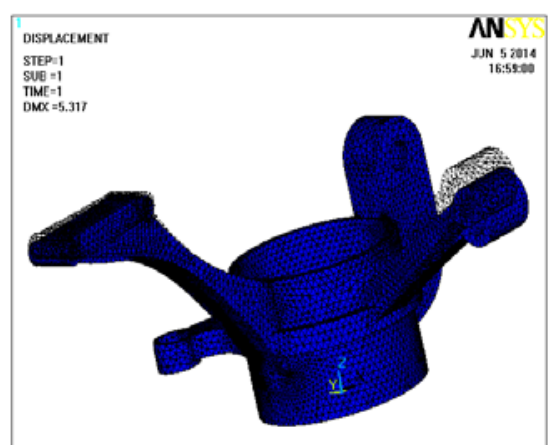

(a) Displacement Distribution Map

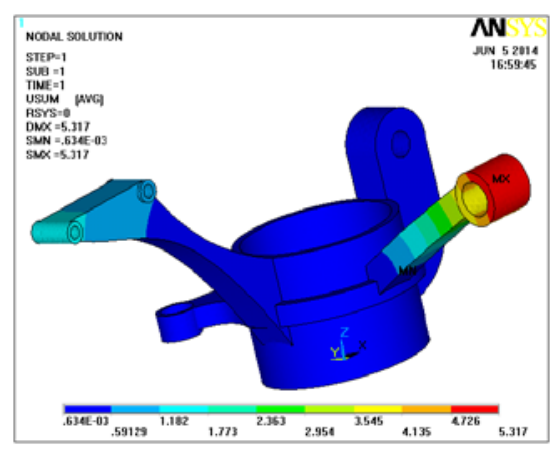

(b) Displacement Moir Map

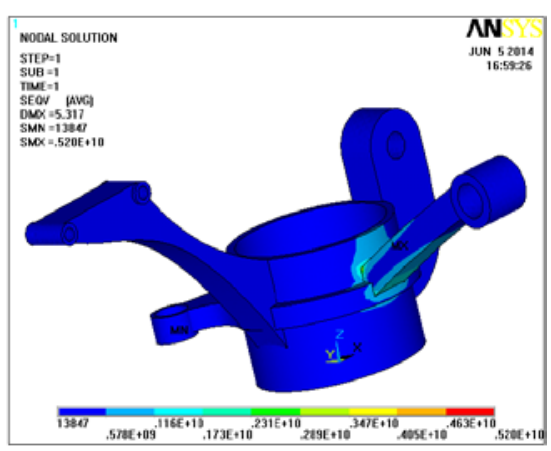

(c) Stress Distribution Map

Fig. 4 Finite Element Calculation Results in Condition 2

It can be seen from Fig. 4, in condition 2, the values of deformation and displacement are largest on the top of damping arm of the steering knuckle, can reach $5.317 \mathrm{~mm}$, which shows that the design here is reasonable. The maximum stress point occurs in the root of damping arm, whose value is $520 \mathrm{MPa}$, which is far less than material yield strength $1000 \mathrm{MPa}$, so the damping arm will not yield.

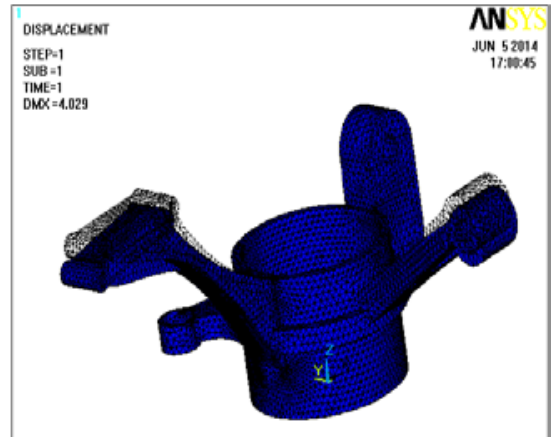

(a) Displacement Distribution Map

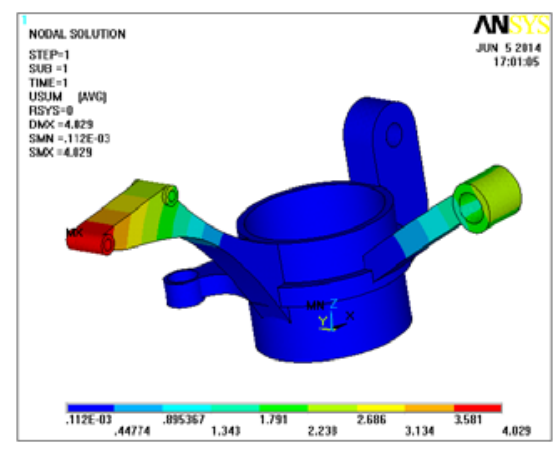

(b) Displacement Moir Map

Fig. 5 Finite Element Calculation Results in Condition 3

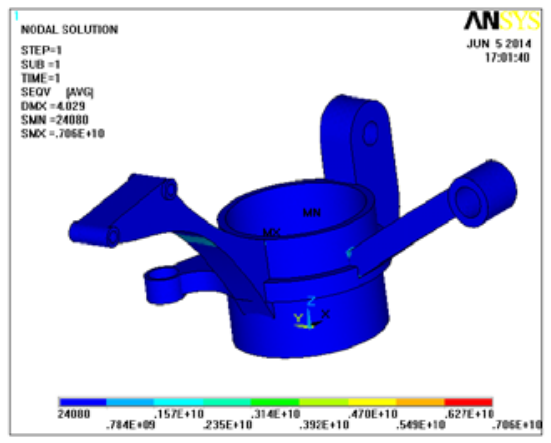

(c) Stress Distribution Map

It can be seen from Fig. 5, in condition 3, the values of deformation and displacement are largest on the top of damping arm of the steering knuckle, can reach $2.029 \mathrm{~mm}$, which shows that the design here is reasonable. The maximum stress point occurs in the top of damping arm, whose value is $706 \mathrm{MPa}$, which is less than material yield strength $1000 \mathrm{MPa}$, so the damping arm will not yield.

\section{Fatigue Strength Analysis on Steering Knuckle}

In this paper, the prediction on the fatigue life of the steering knuckle is based on the elastic-plastic theory and Miner's linear cumulative damage rule. According to Miner's linear cumulative damage rule, it is assumed that the cumulative damage and the number of stress cycles have a linear relationship, and when the cumulative damage reaches 1 , material damage occurs. It can be expressed by a mathematical expression as [6]:

$$
D=\sum_{i} \Delta D_{i}=\sum_{i} \frac{n_{i}}{N_{i}}=1
$$

here, $\Delta D_{i}$ is the damage index under the i-th level constant amplitude cyclic stress whose amplitude is $S_{i}, n_{i}$ is the times of cycles on a corresponding level, and $N_{i}$ is fatigue life under $S_{i}$. The material of the steering knuckle is 40CrNiMoA.

The analysis results are shown in Table 2. 
Table 2 Analysis Results of Knuckle Fatigue Life under Three Limit Conditions

\begin{tabular}{cccc}
\hline Load Condition & Node & Cycle Times of Loading & Fatigue Longevity Quotiety \\
\hline Condition 1 & 37 & 375000 & 0.93750 \\
Condition 2 & 158 & 300000 & 0.75000 \\
Condition 3 & 37 & 375000 & 0.93750 \\
\hline
\end{tabular}

It can be seen from Table 2, that the values of the fatigue life application factor are all less than 1 . According to the linear cumulative damage rule, only when the damage accumulation reaches 1 , does material damage occur, thus, in the three conditions above, the steering knuckle which works under 300000 times of cyclic loading will not fail at all.

\section{Conclusion}

In this paper, finite element analysis is applied to analyze the deformation and stress distribution in a steering knuckle under conditions of three kinds of limit load. In combination with fatigue strength theory, a fatigue life application factor under 300000 times of loading cycles is calculated. The following conclusions are gained:

1) Strength analysis is conducted using ANSYS. It can be seen that under different conditions, displacement distribution maps, displacement moir maps, and stress distribution maps are different, and also the maximum displacement and maximum stress values are different. However, the maximum stress values under different conditions are all within the yield strength, so the steering knuckle does not yield and strength damage will not occur.

2) Fatigue life factors are calculated based on ANSYS and linear cumulative damage theory. It can be concluded that the maximum fatigue life application factor is 0.93750 , less than 1 , that is, fatigue damage will not occur under 300000 times of loading cycles in all of the three conditions.

3 ) In the process of simulation, a dangerous point is found, and it is the main cause of the initial crack, crack extension, and the flowing fatigue damage. The main way to solve this question is to: increase the transition fillet radius, relieve the stress concentration, and reduce the surface roughness. Surface quality to some extent also affects the fatigue strength of the parts, so reducing the surface roughness can reduce or avoid the generation of defects, thereby improving the fatigue life. Within a certain range, improving the parts surface hardness of the dangerous area on the parts surface can strengthen the anti-fatigue properties of parts. For this purpose, surface hardening methods can be used, such as carburizing, nitriding, shot peening etc.

\section{References}

[1] Ying Zheng. Process Design of Automobile Steering Knuckle [J]. Economic Vision. 2013(6).(In Chinese)

[2] Wei Peng, Xiaoxiong Jin, Shuguang Zuo. Fatigue Life Prediction of a Car's Rear Axle Based on FEM Analysis [J]. Automotive Engineering. 2004, 26 (4). (In Chinese)

[3] Fei Li. Research on Durability Life Prediction of Passenger Car's Steering Knuckle [D]. Changchun: Jilin University Ph.D. Thesis 2010. (In Chinese)

[4] Wei Tang. Molding Process Simulation and Mold Design of Automotive Knuckle [J]. Forging. 2009,44 (2). (In Chinese)

[5] Aijun Hu, Baozhan Lv. Development Tendency of Vehicle Steering System [J]. Tractor \& Farm Transporte. 2011(12). (In Chinese)

[6] Yanwei Wang, Jiwei Luo, Jun Ye, etc. FEA Based fatigue analysis and Its Application [J]. Machinery Design \&Manufacture. 2008(1). (In Chinese) 